\title{
Feiern Sie den Kongressauftakt mit uns!
}

\section{Uhr: Den ersten Kon- gresstag in der Industrie- ausstellung ausklingen lassen}

Leiten Sie nach den RöKo-Sessions den gemütlichen Teil des Abends ein - beim Kennenlern-Empfang in der Industrieausstellung um 18 Uhr! Machen Sie noch einen entspannten Rundgang, und kommen Sie ins Gespräch, denn noch vor dem RöKo-Feier-Abend laden die Firmenvertreter Sie herzlich ein zu einem Empfang. Die ausstellenden Firmen freuen sich auf Ihren Besuch! (Es entstehen keine weiteren Kosten.)

\section{Uhr: Buffet und Acts genießen}

Vom Kennenlern-Empfang in der Industrieaustellung geht es ab 19 Uhr weiter mit dem RöKo-Feier-Abend. Das PantomimeDuo Bastian und Pan begrüßt und begleitet die Besucher den ganzen Abend - mit einem klassischen Pantomime Walk Act, und zwar schick im Frack.

Etwas Magie gefällig? Dann freuen Sie sich auf eine bei mehreren Zauberwettbewerben ausgezeichnete Zauberin - und es gibt nur wenige davon in Deutschland! Mit Close-up-Zauberkunst und Kartentricks wird Michelle Zaubert durch die Besuchermengen spazieren und Sie mit Sicherheit faszinieren!

Außerdem wird die Karikaturistin und Schnellzeichnerin FREDICELLI während des gesamten Feier-Abends anwesend sein: Bei



Feiern Sie mit uns den zweiten Leipzig-RöKo (copyright: DRG).

ihr können Sie sich Ihr Charakterbild verblüffend schnell und humorvoll zeichnen lassen!

\section{Ab 21.30 Uhr: Party!}

DJ FONG KAO aus Hamburg wird den RöKoFeier-Abend wieder mit den besten Beats versorgen. Besucher, die sich an großartige Hamburger RöKo-Feier-Abende erinnern, können sich jetzt freuen! Ein weiteres Highlight, dass er den RöKo 2017 wieder gemeinsam mit uns rocken wird. Zuerst untermalt FONG KAO den Feier-Abend-Beginn mit angenehmer Hintergrundmusik, und ab 21.30 Uhr darf jeder das Tanzbein auf dem Dancefloor schwingen!

Lassen Sie uns gemeinsam einen grandiosen Kongressauftakt feiern!

\section{ALLE INFOS AUF EINEN BLICK:}

\section{Kennenlern-Empfang}

Wann: Mittwoch, 24. Mai 2017 | ab 18:00 Uhr

Wo: Industrieausstellung, Halle 2, $\mathrm{CCL}$

Die ausstellenden Firmen freuen sich auf Ihren Besuch! Der KennenlernEmpfang geht zeitlich nahtlos in den RöKo Feier-Abend über.

(Für den Kennenlern-Empfang entstehen keine weiteren Kosten.)

Feier-Abend

Wann: Mittwoch, 24. Mai 2017 | 19 bis $24 \mathrm{Uhr}$

Wo: Foyer $1, \mathrm{CCL}$

(Rückfahrt nach Leipzig mit Straßenbahn, S-Bahn oder Taxi)

Eintritt: $45 €$ | Studenten $20 €$ | Buffet und Drinks inklusive 